\title{
Ninguém ouviu um soluçar de dor: violência racial na narrativa literária de Nei Lopes
}

DOI: https://doi.org/10.22409/pragmatizes.v10i18.40560

Cláudio do Carmo ${ }^{1}$

Resumo: Este artigo trata das relações pessoais e consequentemente raciais assentadas no dogmatismo de poder que faz com haja uma interpretação corrente do juízo correto mas cínico, exposto na ficção narrativa de Rio Negro 50, do escritor carioca Nei Lopes. A narrativa, ao tratar de passagens cotidianas, problematiza o usual e chama a atenção para a invisibilidade negra, bem como a violência simbólica historicamente construída e perpetrada por séculos no imaginário brasileiro.

Palavras chave: violência simbólica; resistência; Nei Lopes; literatura contemporânea.

Nadie escuchó un sollozo de dolor: violencia racial en la narrativa literaria de Nei Lopes

Resumen: Este artículo trata sobre las relaciones personales y consecuentemente raciales basadas en el dogmatismo del poder que conduce a una interpretación actual del juicio correcto pero cínico, expuesto en la ficción narrativa de Rio Negro 50, por el escritor de Río de Janeiro Nei Lopes. La narrativa, cuando se trata de pasajes cotidianos, problematiza lo habitual y llama la atención sobre la invisibilidad negra, así como la violencia simbólica históricamente construida y perpetrada durante siglos en la imaginación brasileña.

Palabras clave: violencia simbólica; resistencia; Nei Lopes; literatura contemporánea.

No one heard a sob of pain: racial violence in Nei Lopes' literary narrative

Abstract: This article deals with the personal and consequently racial relations based on the dogmatism of power that leads to a current interpretation of the correct but cynical judgment, exposed in the narrative fiction of Rio Negro 50, by the Rio de Janeiro writer Nei Lopes. The narrative, when dealing with everyday passages, problematizes the usual and draws attention to the black invisibility, as well as the symbolic violence historically constructed and perpetrated for centuries in the Brazilian imagination.

Keywords: symbolic violence; resistance; Nei Lopes; contemporary literature.

\footnotetext{
${ }^{1}$ Claudio do Carmo Gonçalves. Doutor em Ciências da literatura / UFRJ. Professor Titular de Literaturas / Universidade Estadual da Bahia/ UNEB, professor junto a PPGEL da Universidade Estadual de Feira de Santana/UEFS, Brasil. claudiodocarmog@gmail.com - http:/orcid.org/00000003-3359483X
} 
Ninguém ouviu um soluçar de dor: violência racial na narrativa literária de Nei Lopes.

- Mas é ele mesmo?

- É , sim! Não tá vendo?

- crioulo safado! Covarde!

- Entregou de bandeja, né, seu merda?

- vendido!

- Frouxo!

-Viado! Filha da puta!

[...]

- É ele mesmo?

-Não tá vendo a cara?

- Olha a cara dele.

(LOPES, 2015, p.15)

A cena é real, embora figure no romance Rio negro 50 de Nei Lopes. Remete a um caso fortuito, desses que vemos todos os dias nas grandes cidades. O recorte temporal dos anos 1950, pouco mudam na estrutura apreendida pela cena. Uma violência gratuita e incisiva, bem como inequívoca, já que balizada por uma convicção de valores morais que faz com que haja uma completa identificação naquelas pessoas que animam e dão causa ao fato.

No caso da ficção, trata-se de uma cena resultante da trama principal do romance. O Brasil sediara a Copa do mundo de futebol de 1950, logrando êxito até a partida final, quando enfrenta a então seleção campeã olímpica, com alto prestígio à época, o Uruguai. Na partida final, e isto é história, a seleção brasileira perde por $2 \times 1$ de virada, diante de um estádio do Maracanã lotado por 100 mil pessoas, ainda em obras, pois recém construído para ser o maior do mundo,atônito. Ressalte-se que é o Brasil, é mais que a seleção brasileira de futebol, ou como se acostumou chamar, o país de chuteiras. Isto dá a dimensão de como era tratada a partida final, bem como os personagens daquela partida, prestes a se tornarem heróis.

Alguns detalhes dessa história comum devem chamar a atenção, além do já mencionado significado. Há pouco mais, em termos históricos, dos cem anos da abolição da escravatura, vindos de uma Grande guerra mundial, cuja supremacia ariana fora levantada e derrotada, mas que deixou suas marcas inconfundíveis, a presença de negros no futebol era saudada com alguma parcimônia. A visão geral era tratar-se de um fenômeno atípico. Ainda estavam recentes na memória nacional, sobretudo carioca, o pó-dearroz do Fluminense Futebol Clube, que diz-se ganhou 0 apelido por obrigar um jogador negro a se "pintar" de pó de arroz e assim esconder a cor 
natural da pele. Era recente também a popularidade do Clube de regatas Vasco da Gama, que abrira sua instalações e futebol aos negros, em grande maioria da população marginal da cidade.

A então seleção brasileira de futebol, tinha alguns negros, e algo raro até os dias de hoje, um dos principais era o goleiro, Bigode. Assim, naquela tarde de julho de 1950 o Brasil perde inesperadamente para 0 Uruguai, contrariando a expectativa geral, e o principal do "culpado" pela derrota é o goleiro Bigode,cuja falha no ultimo gol não é perdoada pela torcida, a que estava presente no Maracanã, bem como aquela imensa maioria que assistiu pelo rádio.

O episódio retratado se passa no dia seguinte à fatídica derrota, em que um homem negro, na estação de trem da Central do Brasil, é "confundido" com o goleiro Bigode, dando início ao mal entendido que culminaria no seu linchamento por populares e a consequente morte. Um tribunal moral e simbolicamente perverso resolve em poucos minutos 0 que fazer com aquele homem negro que "só podia ser ele" entregou o jogo do Brasil.
A situação trazida através da narrativa visceral de Nei Lopes, expõe além de tristes estatísticas envolvendo negros no país, o preconceito, a discriminação e uma violência simbólica, por que quase imperceptível, apoiada no lugar comum do negro como uma escória social, cujos pressupostos históricos contribuíam para acelerar e aprofundar a interpretação mais vil.

Nei Lopes se dedica a destrinchar as mazelas do mundo invisível ou marginal a que o negro se encontra na sociedade brasileira, com uma produção vasta, situada entre a ficção , a composição musical, na qual se destaca com alguns dos grandes sucessos da música popular brasileira; e ensaios que refletem uma profunda e complexa pesquisa sobre a memória de raízes afro no Brasil. Deste modo, especialmente neste romance, nos vemos diante de uma pesquisa intrigante que aponta para uma dor que não é ouvida, nem bem sentida por aqueles que não são negros.

$\mathrm{Na}$ vivência social à mostra na narrativa apressa-se a conclusão dogmática que opõe negros e não negros, em que a afetividade impõe uma região identitária assentada nas 
dores e experiências antepassadas. É verdade que as agruras da raça são matizadas, de maneira a não deixar nítida nenhuma relação de desigualdade, culminando na narrativa predominante que revela, com certo cinismo, o aparente apaziguamento social, cujo maior lema é de não haver racismo no país. Evidentemente o que se tem é uma relação política, em que historicamente aqueles que dominam deram a sua interpretação e prática incontestável ao status cotidiano.

Assim, complexas questões desafiam a memória e a identidade construídas no interior do debate sobre o conceito de raça e etnia, não por acaso e por conseguinte, uma parcela significativa da comunidade negra, de origem africana, estabelece-se e promove uma resistência velada à dominação cultural ocidental de características acentuadamente colonizadora, como se pode depreender das suas narrativas.

Para além dos guetos e marginais estereotipados da cultura negra, especialmente situados no Rio de Janeiro da década de 1950, a obra ilumina uma certa intelectualidade que faz contraponto a este estereótipo ao dimensionar a construção de uma identidade que nasce da memória de ancestralidade comum e, ao mesmo tempo, é capital para resistência frente a grupos dominantes.

A discussão se instala a partir de um contraponto teórico que se faz necessário pontuar, que é a noção de literatura negra ou afro-descendente no Brasil que legitimaria os estudos de inserção da narrativa e/ou do autor. $\mathrm{O}$ próprio conceito de África surge como uma primeira pergunta que deve ser respondida e neste sentido é clara a remissão à representação geográfica e política que o continente africano estabelece com suas fronteiras, nações e culturas, muitas vezes sobrepostas, o que acarreta entre outros problemas, conflitos de natureza étnico-racial e cultural, além, obviamente, de conflitos territoriais. Essa África mapeada politicamente com suas culturas tão iguais e tão diferentes, transcende 0 território numa espécie de abstração imaginária que alcança outras culturas fora do alcance geográfico e alimentando um simbólico de dimensões inimagináveis.

É certo que a temática de fundo racial reitera as discussões no universo dos países africanos, sobretudo na África negra; sim pois há 
CARMO, Cláudio do. Ninguiém ouviu um soluçar de dor: violência racial na narrativa literária de Nei Lopes. PragMATIZES - Revista Latino-

Americana de Estudos em Cultura, Niterói/RJ, Ano 10, n. 18, p. 266-277, out. 2019 a março 2020.

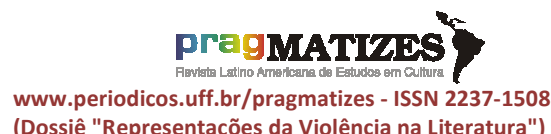

(Dossiê "Representações da Violência na Literatura") uma África branca, notadamente ao norte do continente, que sintomaticamente, se apressa na aproximação com o Ásia ou oriente médio. Pois bem, essa África negra, e aqui vou me dedicar especificamente, à matriz de língua portuguesa, ou seja, países que foram colonizados pela Metrópole europeia, Portugal, tem em comum além da língua predominante (não pacífica), a portuguesa; uma série de outros aspectos que de algum modo podem ser abordados no sentido de refletir uma possível identidade, ou noção de semelhança que relacionam entre si estes países, tais como a pele negra, o comportamento social e aspectos políticos.

Sabe-se que a organização de um processo identitário pela língua é silencioso mas altamente eficaz, já que se utiliza de um mecanismo simbólico extremamente poderoso, por sua aparente naturalidade. Com efeito, o mecanismo na feliz acepção de Barthes (1978) é chamado de império da língua, e que demonstra bem como a língua age de forma mascarada no processo de dominação. Desta forma, a utilização da língua serve como esse mecanismo de império, ao mesmo tempo que a consciência deste poder por parte de grupos supostamente dominados, leva a uma consciência de resistência, como um desafio a essa maneira como foi forjada a cultura, especialmente a linguística, essa a melhor palavra, já que fruto de uma arbitrária colonização encontrou resistências de toda ordem, culminando com o incômodo de línguas nativas conviverem concomitante à língua oficial portuguesa e, em certas regiões, serem inclusive mais frequentes.

Os países africanos de matriz portuguesa, aqueles que tiveram origem linguística social e histórica através da colonização de Portugal, são cinco, e todos situam-se num raio geográfico do nordeste do continente africano, a África subsaariana ${ }^{2}$, para o sul e sudoeste. Assim, esta África portuguesa, é negra por excelência e parte daí todo a reflexão sobre como se dá seu processo identitário.

Angola, Moçambique, Guiné Bissau, São Tomé e Príncipe, e Cabo Verde, parecem ter pouco em comum,

\footnotetext{
${ }^{2}$ Refere-se a todo o continente africano situado abaixo do deserto do Saara, com seus cerca de $9.000 .000 \mathrm{~km}^{2}$ (nove milhões de $\mathrm{Km}^{2}$ ) o que acaba por distinguir uma barreira natural entre um continente negro, ao sul, abaixo do Saara, e um continente branco, ao norte, acima do Saara, cujas características socioculturais o aproximam do oriente médio.
} 


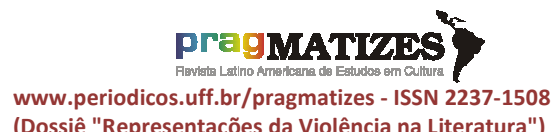

(Dossiê "Representações da Violência na Literatura") a não ser o fato da origem portuguesa

e de estarem situados no mesmo continente, daí a tendência mais forte nos estudos recentes, de distinguir as pesquisas que investigam os fenômenos socioculturais e políticos que enraízam os fatos históricos a que estão relacionados. Mas aqui, me permito contrariar a infundada tendência, e pontuar o que os une, como países, nações e sociedades que comungam de um mesmo espírito original e que reverberam como constante simbólica os limites da África negra.

A partir de uma origem que não se distingue muito, quanto ao processo de colonização, os países lusófonos de África são fruto da expansão marítima portuguesa nos séculos XV e $\mathrm{XVI}$, o que explica em grande parte seus desenvolvimentos de anatomia particular mais semelhantes entre si.

Essa semelhança passa por uma história social de colonização e de condições adversas que em muito contribui para uma psicologia nacional. Não obstante, os fatores que desequilibram uma identidade africana são muitos e devem ser considerados, mormente se atentarmos para 0 conceito de identidade, conforme assinala Pollak (1992, p. 208 ):

Ninguém pode construir uma autoimagem isenta de mudança, de negociação, de transformação em função dos outros. A construção da identidade é um fenômeno que se produz em referência aos outros, em referência aos critérios de aceitabilidade, de admissibilidade, de credibilidade, e que se faz por meio da negociação direta com outros.

A identidade, então, é fundada a partir do outro, seja por uma autorização, seja por uma negociação tácita, que muitas vezes obedece apenas a um rito, cujos resultados são previsíveis.

Se a própria identidade africana se mostra fraturada como vimos, supõe-se que seu acondicionamento como uma recepção simbólica envolva problemas de tal ordem. E é esta a tônica que passamos a observar na literatura oriunda da matriz africana expressa fora do continente africano, especialmente no Brasil.

Em termos ficcionais, Maria Firmina dos Reis, em 1859, em São Luís do Maranhão, publica o primeiro romance de matriz africana no Brasil, já no sentido da crítica, o estudo pioneiro se deve ao sociólogo francês Roger Bastide, cujos trabalhos relacionados à cultura negra são notórios, dentre estes " $A$ poesia negra 
no Brasil', publicado em 1943, que aponta para a primeira sistematização ao instaurar um pensamento vinculado às experiências da cultura negra no país. As duas publicações têm em comum, além do pioneirismo apontado, uma perspectiva de mapear o universo dessa literatura produzida no Brasil. $E$ eis a primeira noção que deve ser destacada. Ao falarmos de literatura negra ou afro-descendente quais critérios estarão sendo considerados nesta expressão conceitual. Eduardo de Assis Duarte (2011), fazendo referência a Octávio lanni, para quem "o negro é o tema principal da literatura negra" destaca que tais critérios são constituídos por um elencos de fatores, tais como o tema, visto que a literatura negra apreende um movimento temático amplo em que o negro e suas especificidades é a base. Mas não se restringe ao tema, pois neste contexto há de se considerar também a autoria marcada pela escrita proveniente de autores afro-descendentes; o ponto de vista que registra o lugar de enunciação do sujeito, de onde se fala, ou seja, sugere que haja uma visão de mundo, uma identificação com a história e a cultura. Pode-se ainda arrolar dois tópicos que auxiliam nesta construção da noção literária afrodescendente: a linguagem que acena para uma dicção própria no modo peculiar de lidar com o universo afro; e por fim um público leitor apto a consumir esta literatura de herança africana transfigurada pelas condições locais do Brasil. Numa leitura abrangente destes tópicos parece óbvio que isoladamente eles se precarizam, nenhum deles se basta enquanto categorias que possam identificar ou definir uma literatura negra ou afro-descendente. A possibilidade mais apreciada estaria na interação, no conjunto destes elementos, mesmo assim parece nítido que alguns destes tópicos são problemáticos do ponto de vista conceitual, vejamos: uma literatura de temática negra inclui, mas sua abrangência é tamanha que ela pode se desfigurar ao se distanciar sobremaneira da proposta que a originou. A autoria exclui, pois restringe-se aos herdeiros objetivamente afros. De outro modo, a autoria negra supõe um autor negro. Mas mesmo este autor parece sofrer restrições, já que precisa estar identificado com as causas e universo 
CARMO, Cláudio do. Ninguiém ouviu um soluçar de dor: violência racial na narrativa literária de Nei Lopes. PragMATIZES - Revista Latino-

Americana de Estudos em Cultura, Niterói/RJ, Ano 10, n. 18, p. 266-277, out. 2019 a março 2020.

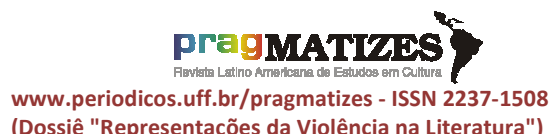

(Dossiê "Representações da Violência na Literatura")

É neste cenário que a trama se desenvolve, com forte dicção histórica, trazendo à tona a África e fincando-a num espaço notoriamente politizado do Rio de janeiro, as imediações da Cinelândia.

O espaço, como um lugar-dememória, já carrega toda a carga política da dinâmica social e é a partir deste cenário que emergem lugares símbolos como a "Café e Bar Rio Negro", de clara ironia ao Rio branco, o barão, precursor da diplomacia nacional e um dos orgulhos intelectuais do país. Há ainda o "BarRestaurante Abará", cujo nome guarda em si as origens africanas. Saliente-se que as referências africanas constantes na narrativa, muitas vezes são seguidas de explicações típicas de uma pesquisa acadêmica, ora na voz de um narrador em terceira pessoa que conhece a todos e amplia seu horizonte de observação ao não só registrar os fatos, mas tecer comentários às vezes sutis às vezes irônicos, mas sempre num nítido posicionamento do lugar em que se fala.

O ponto de vista, assim, é fundamental para a narrativa e carrega consigo um viés político ao deixar 
claro posicionamentos ideológicos: "Do outro lado da Avenida, a uns poucos duzentos ou trezentos metros do Rio Negro, fervilha o Abará, maldosamente apelidado de Café e bar Colored, com o eufemismo usado para designar os moreninhos." (LOPES, 2015, p. 45). Ora também estes comentários se dão através de personagens, muitos, numa galeria enorme que envolve indivíduos puramente ficcionais e outros tantos históricos que marcaram a intelectualidade negra no país, e são agrupados em torno do espaço dos bares, constituindo deste modo a força simbólica dos lugares-memória. São os casos do dramaturgo e teatrólogo Abdias do Nascimento, sociólogo Guerreiro Ramos, do folclorista Edson Carneiro, dos músicos Pixinguinha, Donga Paulo Moura e Jonny Alf, que estabelecem uma relação orgânica com aquilo que se fala, como é o caso deste trecho preconizado por Edson Carneiro: "Na África, entre o povo nagô, chama abalá; e é um bolinho de arroz. E acará é de feijão. Daí, veio o acarajé. Que é frito, e não cozido." (LOPES, 2015, p. 50)

O tom explicativo, algo de doutoral, adquire relevância quando se observa que o narrador se embrenha pela trama através de estratégias ficcionais que lhe permite estar na voz dos intelectuais que frequentam 0 Café-bar Rio Negro ou o Restaurante Abará, e desta forma emitir opiniões e posições que reforçam 0 tom identitário no interior de um grupo negro que se aproxima não como uma comunidade, já que como vimos esta identidade africana é fraturada em plena África, mas com um sentimento de solidariedade e ancestralidade que termina por Ihes unir em certo afeto ou identificação. Para tanto, este narrador se move entre o conhecimento escolar e a memória de pertencimento. Com uma marca configurada em resistência ao contrapor-se à história oficial, seja através dos intelectuais negros que destilam seus conhecimentos, seja através de anônimos, que ganham relevância na narrativa ao emprestarem força através da oralidade e da experiência genuína daí decorrente, os personagens são instigados a tecer comentários $\mathrm{e}$ descrições que guardam muito da memória africana, revelando uma ligação espiritual dominante.

Quem me chamou a atenção pra isso foi uma patroa que eu tive, uma grande artista, muito culta. Chamava-se Etiópia de Oliveira Houston; porque era filha de uma 


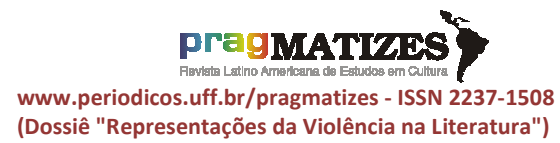

A cena impressiona e guarda a família amulatada, mas era casada com um maestro e compositor americano. Era cantora lírica, de ópera, mas a especialidade era folklorr... Isa não fala folclore, como todo mundo. Ela diz folk lorr, separando os elementos da palavra e metendo no fim um erre vibrante. (LOPES, 2015, p.54)

passado em comum de uma experiência africana de açoite e percalços coloniais parece emergir no início da trama, quando um grande mal-entendido é narrado. Trata-se do dia seguinte à decantada derrota do Brasil para o Uruguai em pleno maracanã na Copa do mundo de futebol em 1950. É manhã de 17 de julho e um jovem negro salta do trem da Central do Brasil, quando é confundido com o jogador Bigode, da seleção brasileira, perseguido por populares e depois de xingamentos e pontapés, o rapaz é linchado.

Espera uns dez minutos; até que o trem encosta e abre as portas, com o chiado característico. Entra sem dificuldade, pois já é de tarde. Procura um canto e senta, encolhido pra esconder a ressaca e a tristeza. Mas os olhares estão no trem também. (...) - Mete-lhe a ripa! Toma, seu puto caga-leite! pra não levantar mais! -na cabeça, não ! na cabeça não! Na cabeça sim! Pra deixar de ser besta! Toma! Que que é isso gente? Vocês vão matar o homem! - É pra matar mesmo! Segura essa, seu merda! (LOPES, 2015, p. 15-17) marca de um grande equívoco. Um homem negro que é confundido com o jogador de futebol, de uma seleção de maioria negra, que cometeu o grande erro de perder a final de uma copa do mundo. Para além da ruína social exposta, a descrição traz à mostra certo desconforto e se insere de maneira pontual numa deformação social que tem origens em uma mentalidade e ideologia de raízes colonizadora, como na observação de Moema Parente Augel (1997, p.183):

Estreitamente ligadas à estratificação social, mas não idênticas a ela, estão no Brasil a questão racial e a procura por parte da população não branca tanto de sua identidade cultural como da ampliação dos seus espaços de ação, numa sociedade norteada pela ideologia do branqueamento e ainda deformada com resquícios da mentalidade colonialista e dominadora.

Assim, nas mesas dos fictícios Cafés da Cinelândia passam todos os tipos de personagens e problemas cotidianos, desde a falta d'água, a crescente especulação imobiliária, os trens que como navios negreiros, "carregam gente como se fosse boi pro matadouro" e também o preconceito racial, que gera uma discussão atravessada em vários períodos da narrativa. Alguns concordam que há 
racismo no Brasil, outros não tem tanta convicção, mas 0 fato é que 0 linchamento da Central demonstra nitidamente a anulação de qualquer clima amistoso que encubra uma democracia racial, favorecendo 0 argumento de que a abolição da escravatura foi incapaz de inserir 0 negro na sociedade: "Abolição de fachada! Onde já se viu libertação sem condição econômica, sem previdência?". Há quem acredite que a ausência de leis segregacionistas, como nos Estados Unidos, de onde chegam as primeiras notícias sobre Rosa Parks e o movimento pelos direitos civis, possa ser um indício de uma outra realidade no Brasil, que dispensaria tais medidas, ao mesmo tempo que os frequentadores do Café Rio Negro reclamam das esquetes de humor e piadas racistas veiculadas pela Rádio Nacional, a grande mídia da época: "E você já reparou que, no rádio, artista preto dificilmente tem nome? Não tem nome, é só apelido: Blecaute, Caboré, Chocolate, Jamelão, Gasolina, Pato Preto, Risadinha...". (LOPES, 2015, p. 43)

Em linhas gerais, a narrativa de Rio Negro 50, ao completar uma trilogia iniciada com o romance "Mandingas da mulata velha na cidade nova" ; e a "A lua triste descamba" tem no protagonismo negro sua razão. O que parece evidente é que tais obras e notadamente este "Rio Negro, 50" representam uma resistência ao discurso dominante que faz com que o negro, ou afrodescendente esteja sempre em plano secundário, daí a atualidade de uma narrativa que passada nos anos de 1950 traz a memória daquele tempo, e acuse a violência secular que justifique 0 discurso e prática de resistência comumente reivindicado.

Ao pontuar com frequência 0 passado mira-se 0 presente, a contemporaneidade, e a constante atualização das condições de precarização que a condição histórica do negro reveste e dá forma. Tais condições aviltantes são alicerçadas num passado cruel, que está longe de ser ficção, e encontra eco numa atitude senhorial que escamoteia 0 conflito como forma de manter a detenção do poder simbólico e real daqueles que 0 detém.

\section{Referências bibliográficas:}

AUGEL, Moema Parente. A imagem da África na poesia afro-brasileira contemporânea. Revista Afro-Ásia, Salvador, n. 19/20, p.183-199, 1997. 
BARTHES, Roland. Aula. São Paulo:

Cultrix, 1978.

DUARTE, Eduardo de Assis. Literatura afro-brasileira: um conceito em construção. Revista Estudos de Literatura Brasileira Contemporânea, Brasília, n. 31, p.11-23, 2011.

LOPES, Nei. Rio Negro 50. Rio de Janeiro: Record, 2015.

MBEMBE, Achile. Crítica da razão negra. São Paulo : N-1 edições, 2019.

POLLAK, Michael. Memória e identidade social. Revista Estudos históricos, Rio de Janeiro, v. 5, n. 10, p. 200-212, 1992. 